\title{
Mucoceles of the Paranasal Sinuses: MR Imaging with CT Correlation
}

\author{
Pamela Van Tassel ${ }^{1}$ \\ Ya-Yen Lee \\ Bao-Shan Jing \\ Charles A. De Pena
}

The MR findings in six cases of paranasal sinus mucoceles are described. Two basic MR appearances were encountered: either moderate to marked signal hypointensity in the expanded sinuses on T1- and T2-weighted images (four patients) or moderate to marked signal hyperintensity on T1- and T2-weighted images (two patients). These patterns appear to represent inspissated or hydrated sinus contents, respectively. CT correlation revealed hyperdense mucoceles in the decreased MR signal group and hypoor isodense mucoceles in the increased MR signal group. Superimposed allergic Aspergillus sinusitis was also present in two patients with hypointense mucoceles on MR.

The plain radiographic and CT appearance of paranasal sinus mucoceles has been well described [1-6]. To date there have been very few illustrations of MR findings of mucoceles in the literature [7-9]. This paper presents the findings of preoperative MR imaging, with CT correlation, performed in six patients with proved mucoceles.

\section{Subjects and Methods}

Six patients had MR imaging on a GE 1.5-T unit using a spin-echo technique. T1-weighted scans, $600 / 20$ (TR/TE), were obtained in the sagittal plane and frequently also in the coronal and/or axial planes. A long TR series with intermediate and long TE $(2000 / 20,80)$ was obtained in either the coronal or axial plane. Axial and coronal CT scans with $5-\mathrm{mm}$ slice thicknesses were also available in each of the six patients. Three patients had pre- and postcontrast CT scans performed at other hospitals, while the other three had only postcontrast scans at our institution. These latter studies were performed using a bolus of $75 \mathrm{ml}$ of $60 \%$ iodinated contrast material followed by a rapid drip of another $75 \mathrm{ml}$. All six patients underwent surgical exploration of the affected sinuses. In five cases this was accomplished through an external approach, while the remaining patient had craniofacial surgery.

\section{Results}

The results are summarized in Table 1. In two patients the mucocele involved only one paranasal sinus while in the other four patients there was involvement of multiple sinuses. There were nasal and ethmoid polyps in three patients, presumably the cause of mucocele formation after sinus ostium obstruction. In another patient with a frontal sinus mucocele, a small piece of bone was found obstructing the nasofrontal duct at surgery. No cause was found for the mucoceles in the remaining two patients. There was expansion of the mucocele into the adjacent orbit in the four patients who had mucoceles of the anterior ethmoid and/or frontal sinuses. One patient had intracranial extension of mucocele from the frontal sinus into the anterior fossa. This case also demonstrated the most extensive paranasal sinus involvement.

The MR appearance of the mucoceles revealed two basic patterns. The first was

one of moderate to marked hypointensity (relative to white matter) on T1- and T2-
This article appears in the May/June 1989

Received August 8, 1988; accepted after revision November 8, 1988

${ }^{1}$ All authors: Department of Diagnostic Radiology, University of Texas M. D. Anderson Cancer Center, 1515 Holcombe Blvd., Houston, TX 77030. Address reprint requests to $\mathrm{P}$. Van Tassel.

AJNR 10:607-612, May/June 1989

0195-6108/89/1003-0607

(C) American Society of Neuroradiology 
weighted images in the affected sinuses, and was seen in four patients (Figs. 1 and 2). The degree of low signal intensity was always greater on the T2-weighted images and was equivalent to a signal void in three of the four patients. Evidence of an inflamed mucosal lining of variable thickness was seen around the periphery of these sinuses, hypo- to isointense on T1-weighted images and hyperintense on T2- weighted images. Three of these four patients demonstrated diffuse hyperdensity within the mucoceles on noncontrast CT, frequently in a stippled pattern, and with no enhancement after contrast administration (Figs. 1 and 2). The fourth patient in this group had only postcontrast CT, which demonstrated an identical appearance to the hyperdense, expanded sinuses in the other three cases and was believed to represent

TABLE 1: Distribution and Imaging Characteristics of the Paranasal Sinus Mucoceles

\begin{tabular}{|c|c|c|c|c|c|c|}
\hline $\begin{array}{l}\text { Case } \\
\text { No. }\end{array}$ & Sinus(es) Involved & $\begin{array}{l}\text { Precontrast } \\
\text { CT Findings }\end{array}$ & $\begin{array}{l}\text { Postcontrast } \\
\text { CT Findings }\end{array}$ & MR Findings & $\begin{array}{l}\text { Nasal or } \\
\text { Ethmoid } \\
\text { Polyps }\end{array}$ & $\begin{array}{c}\text { Allergic } \\
\text { Aspergillosis }\end{array}$ \\
\hline 1 & $\begin{array}{l}\text { Bilateral sphenoid, } \\
\text { posterior eth- } \\
\text { moid }\end{array}$ & Hyperdense & No change & $\begin{array}{l}\text { Hypointense on T1WI, } \\
\text { signal void on T2WI }\end{array}$ & No & Yes \\
\hline 2 & $\begin{array}{l}\text { Bilateral frontal, } \\
\text { ethmoid, sphe- } \\
\text { noid; left maxil- } \\
\text { lary }\end{array}$ & Hyperdense & No change & $\begin{array}{l}\text { Mixed iso-, hyper-, } \\
\text { and hypointense on } \\
\text { T1WI; predomi- } \\
\text { nantly hypointense } \\
\text { on T2WI }\end{array}$ & Yes & Yes \\
\hline 3 & Right sphenoid & ND & $\begin{array}{l}\text { Hyperdense } \\
\text { (probably } \\
\text { intrinsic) }\end{array}$ & $\begin{array}{l}\text { Hypointense on T1WI, } \\
\text { signal void on T2WI }\end{array}$ & Yes & No \\
\hline 4 & $\begin{array}{l}\text { Bilateral frontal, } \\
\text { ethmoid (left > } \\
\text { right); left maxil- } \\
\text { lary, sphenoid }\end{array}$ & Hyperdense & No change & $\begin{array}{l}\text { Mixed iso-, hyper-, } \\
\text { and hypointense on } \\
\text { T1WI; hypointense } \\
\text { on T2WI }\end{array}$ & Yes & No \\
\hline 5 & $\begin{array}{l}\text { Right frontal, eth- } \\
\text { moid }\end{array}$ & ND & Hypodense & $\begin{array}{c}\text { Mildly hyperintense on } \\
\text { T1WI, markedly hy- } \\
\text { perintense on T2WI }\end{array}$ & No & No \\
\hline 6 & Left frontal & ND & Isodense & $\begin{array}{l}\text { Markedly hyperin- } \\
\text { tense on T1WI and } \\
\text { T2WI }\end{array}$ & No & No \\
\hline
\end{tabular}

Note. $-\mathrm{ND}=$ not done; $\mathrm{T} 1 \mathrm{WI}=\mathrm{T} 1$-weighted images; $\mathrm{T} 2 \mathrm{WI}=\mathrm{T} 2$-weighted images

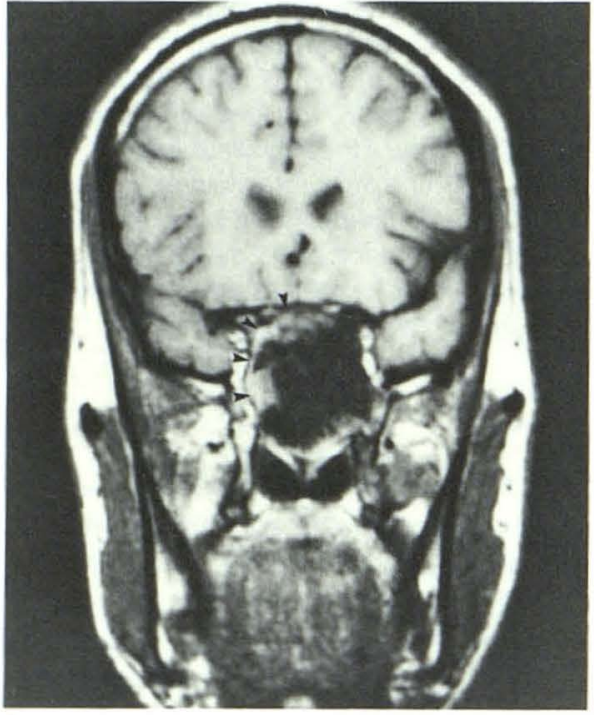

A

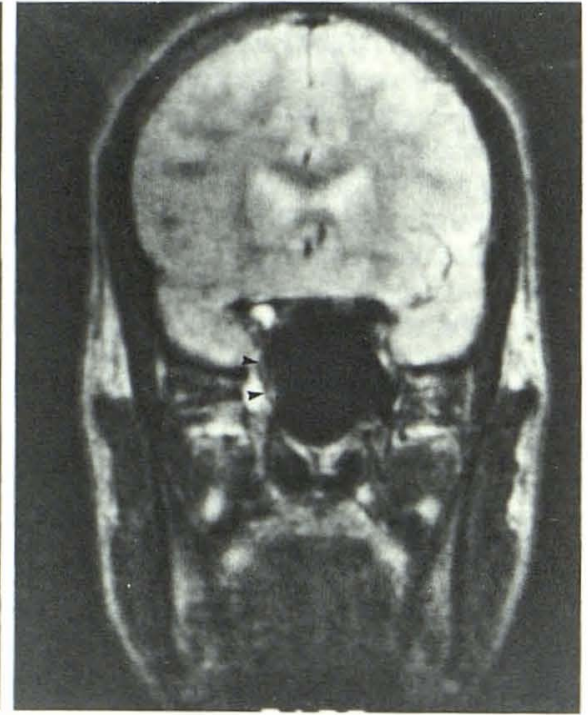

B

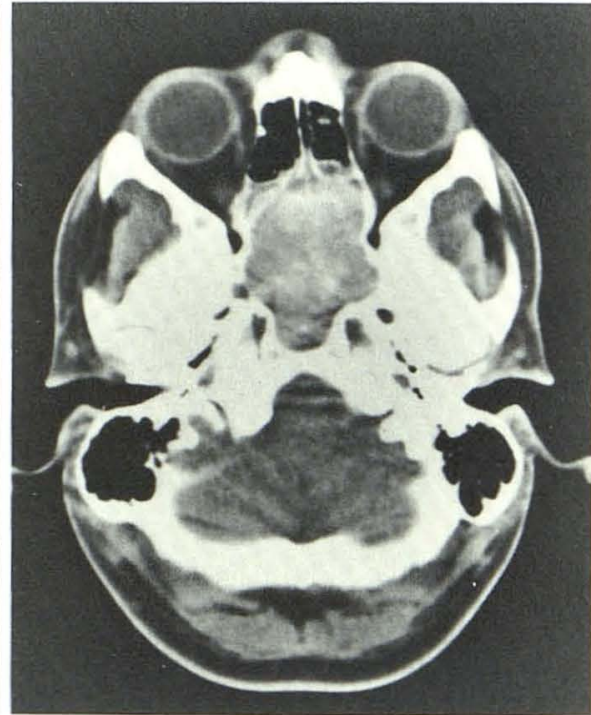

C

Fig. 1.-Mucocele of the sphenoid and posterior ethmoid sinuses.

A, T1-weighted MR image $(600 / 20)$ reveals an expanded sphenoid sinus, which is very hypointense except for material isointense to white matrer around sinus periphery (arrowheads).

B, T2-weighted MR image $(2000 / 80)$ reveals greater hypointensity (signal void) in the sinus. Peripheral rim of brighter signal is less well seen (arrowheads).

C, Noncontrast CT scan demonstrates hyperdense material within expanded sphenoid and posterior ethmoid sinuses. 


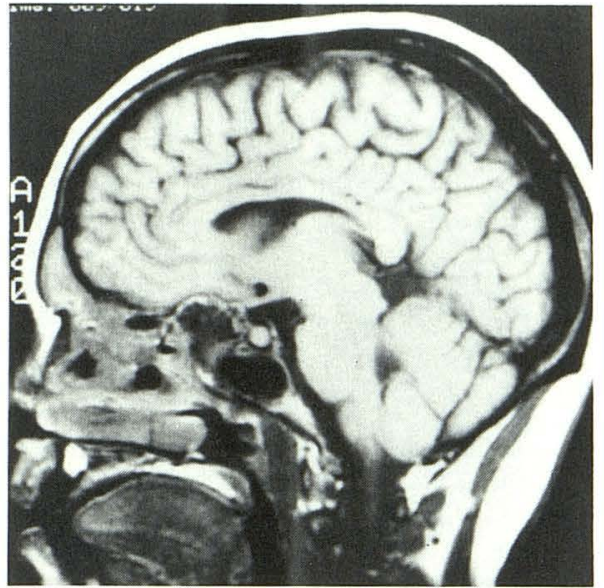

A

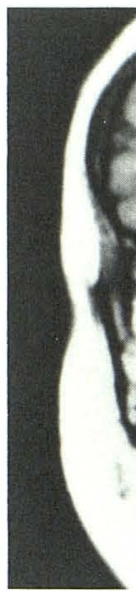

B

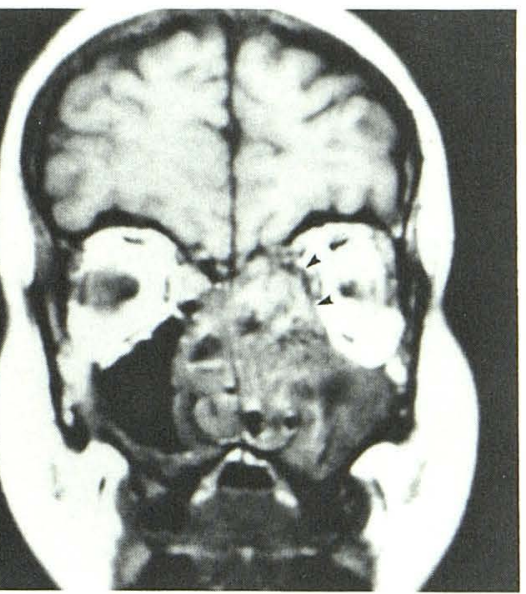

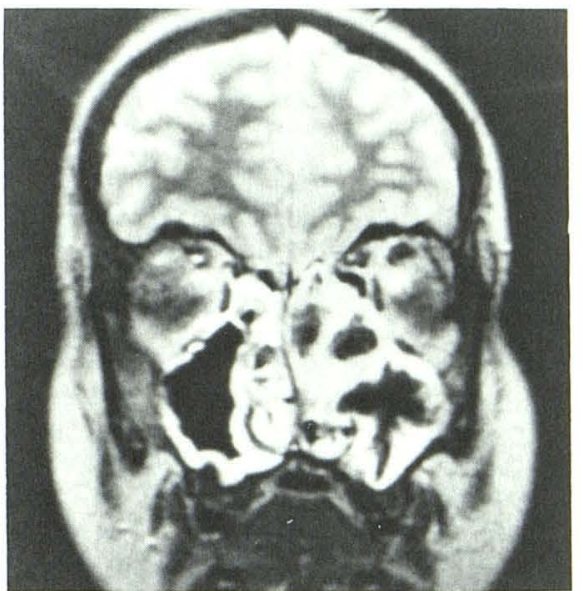

C
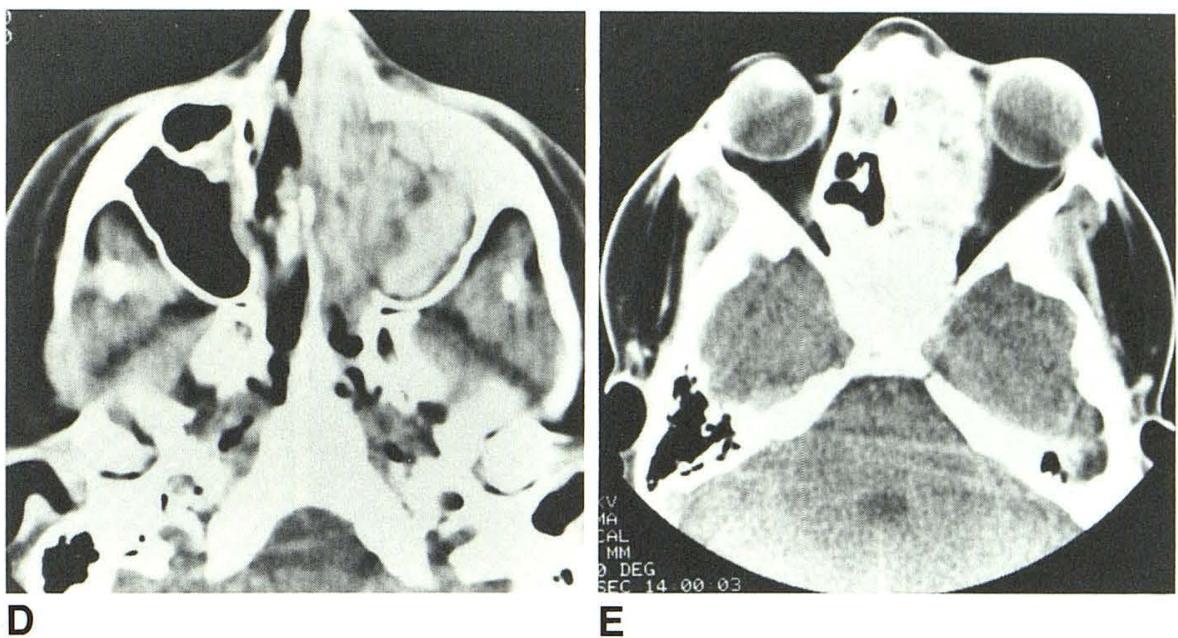

E

Fig. 2.-Nasal and ethmoid polyps with mucocele formation in left maxillary, left ethmoid, and bilateral sphenoid sinuses. Allergic Aspergillus sinusitis also involved these sinuses.

A, T1-weighted MR image $(600 / 20)$ shows expansion of sphenoid and posterior ethmoid sinuses with hypointense contents (sphenoid sinus is not aerated).

$B$, T1-weighted MR image $(600 / 20)$ demonstrates mixed signal intensities in left anterior ethmoids, with bulging of sinus contents into medial left orbit (arrowheads). Left antrum also exhibits heterogeneous signal.

C, T2-weighted MR image (2000/80) shows larger regions of signal void in left antrum and ethmoids and hyperintense inflamed nasal and antral mucosa bilaterally.

$D$ and $E$, Noncontrast CT scans demonstrate hyperdense contents in sphenoid sinuses bilaterally, and maxillary and ethmoid sinuses on the left.

intrinsically hyperdense material within the sinus rather than enhancement. An isodense mucosal lining was seen around the sinus periphery on CT in all four cases.

Review of the surgical and pathologic findings in the first group of patients showed that solid, greenish-brown, mucoid material was present in the involved sinuses in all four cases. In three of the four, the contents were described as inspissated, reflecting hard, dehydrated material. Two of these four patients also had a pathologic diagnosis of allergic Aspergillus sinusitis, which was associated with microscopic CharcotLeyden crystals.

The second pattern, observed in two patients, consisted of signal hyperintensity in the affected sinuses on T2-weighted scans and mild to markedly hyperintense signal on the T1weighted scans (Figs. 3 and 4). The mucoceles in these patients were iso- or hypodense relative to brain on CT without enhancement (Figs. 3 and 4). At surgery, both of these mucoceles were found to be of a fluid consistency and were easily drained or suctioned out. This is in contrast to the solid, inspissated nature of the mucoceles in the first group.

Proton-density-weighted images in both groups of patients were not found to contribute further information relative to that on the T1-and T2-weighted images.

\section{Discussion}

A paranasal sinus mucocele is an airless, expanded sinus that develops after obstruction of the sinus ostium, or, rarely, after filling of the sinus by a distended mucous gland (retention cyst) $[1,4,10]$. These obstructed sinuses contain mucoid secretions produced by the mucosal lining. With the advent of CT, a more thorough evaluation of the location and regional extension of paranasal sinus mucoceles was possible, com- 


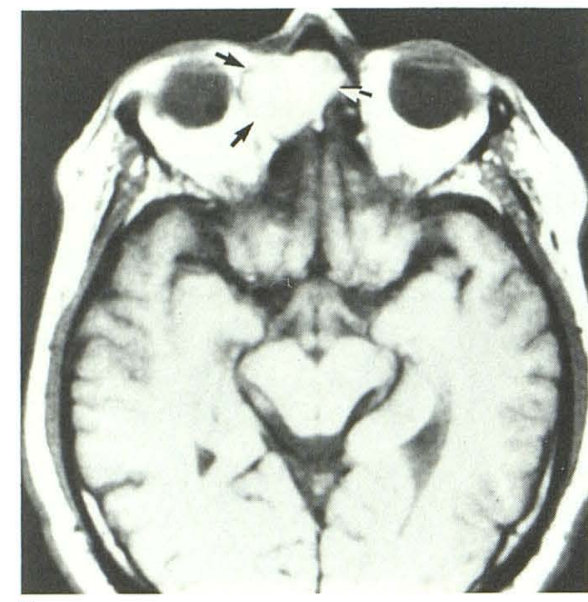

A

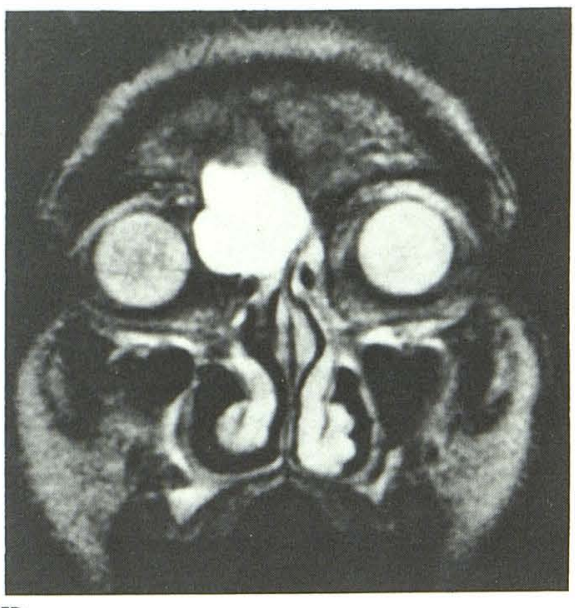

B

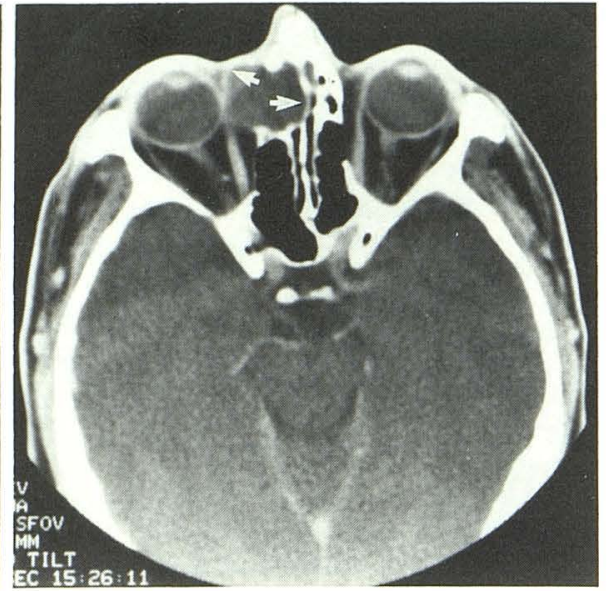

C

Fig. 3.-Mucocele of right frontal and anterior ethmoid sinuses with extension into right medial orbit.

A, T1-weighted MR image $(600 / 20)$ shows expansile, hyperintense abnormality of anterior ethmoids bilaterally, greater on the right (arrows).

$B$, T2-weighted MR image (2000/80) shows greater signal hyperintensity in mucocele and involvement of lower right frontal sinus.

$C$, Postcontrast CT scan shows mucocele to be hypodense with areas of rim enhancement (arrows).

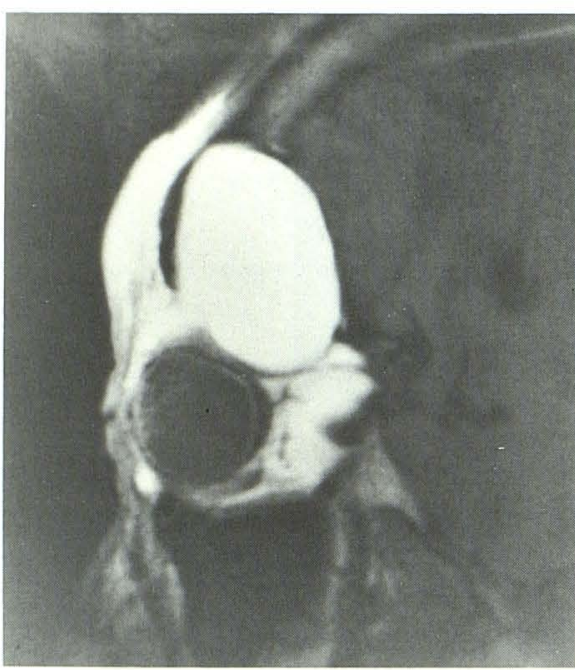

A

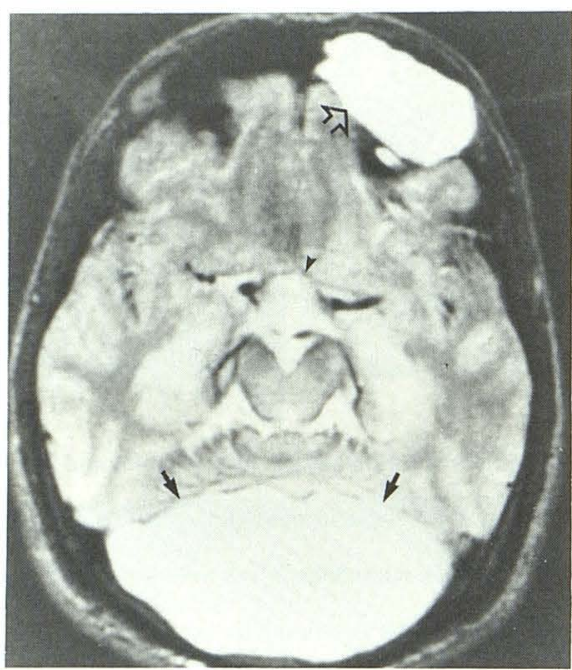

B

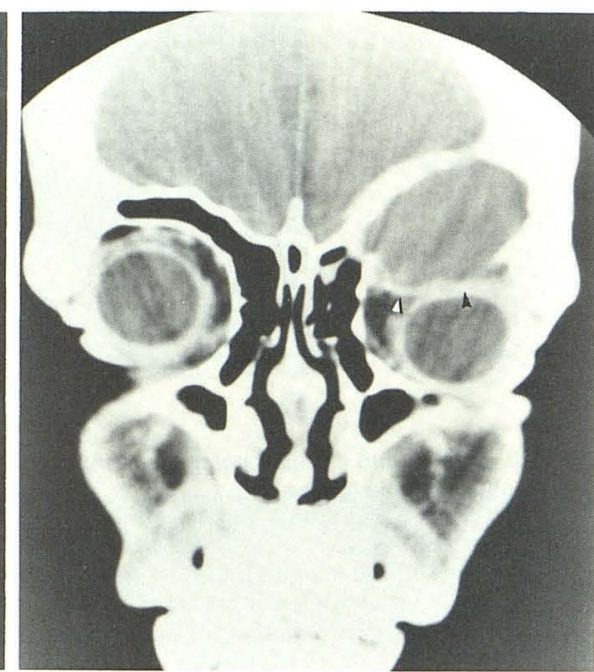

C

Fig. 4.- Mucocele of left frontal sinus.

$A$, T1-weighted surface-coil MR image $(600 / 20)$ shows very hyperintense mucocele expanding left frontal sinus and eroding into superior orbit.

$B$, T2-weighted MR image $(2000 / 80)$ likewise demonstrates hyperintensity in mucocele (open arrow). The patient also has a Dandy-Walker malformation (closed arrows), and hydrocephalus (arrowhead, third ventricle).

C, Postcontrast CT scan reveals isodense mucocele and bone erosion and rim enhancement inferiorly (arrowheads).

pared with plain film and tomographic examinations. MR offers similar excellent delineation of the extent of disease in multiple imaging planes.

The extreme differences in MR signal intensity seen in the mucoceles in this series appear to reflect variable hydration of the mucoid contents of the obstructed sinuses. The four cases that had hyperdense mucoceles on noncontrast CT and hypointense or no signal in these sinuses on MR are consistent with the presence of inspissated mucocele con- tents, which was confirmed at surgery. This dehydrated material has a paucity of available hydrogen protons for the resonance phenomenon, resulting in a lack of MR signal on all pulse sequences. The noncontrast CT findings, which look like multiple fine calcifications, are similar to that seen on CT in mucinous adenocarcinomatous metastases to the brain parenchyma.

The frequency of hyperdense mucoceles on CT in our series $(66 \%)$ is higher than the few cases of hyperdense mucoceles 
Fig. 5. - Conditions with a similar MR appearance to mucocele.

$A$ and $B$, T2-weighted MR image $(2000 / 80)(A)$ and postcontrast CT scan $(B)$ of osteosarcoma of ethmoids and nasal fossa with intracranial extension. Tumor is largely hypointense on MR (arrows in $A$ ) and displays matrix mineralization and areas of enhancement on CT. There are sinus obstruction and mucosal inflammation in the maxillary antra.

$C$ and $D$, T2-weighted MR image $(2000 / 80)$ $(C)$ and postcontrast CT scan $(D)$ in fibrous dysplasia of the ossifying fibroma type. There are dense sclerosis and thickening of the walls of the left maxillary antrum, seen primarily as areas of hypointensity on MR (arrows in C). There is similar involvement of left pterygoid plates (arrowheads in $C$ ).

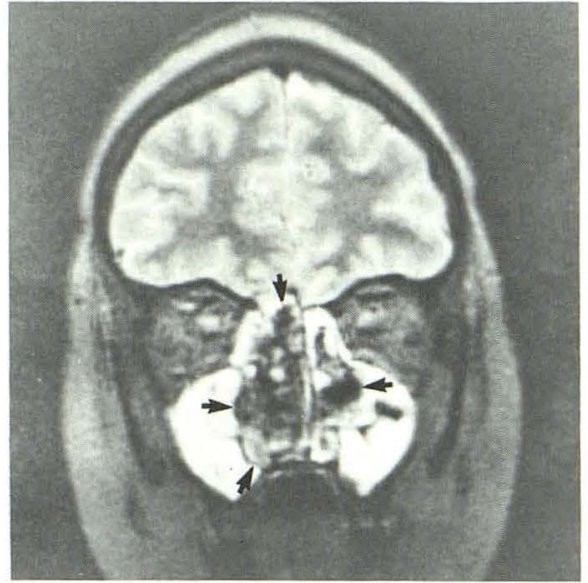

A

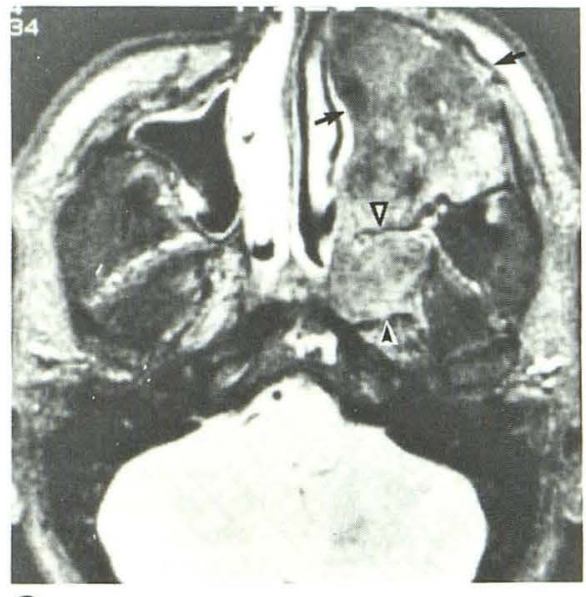

C

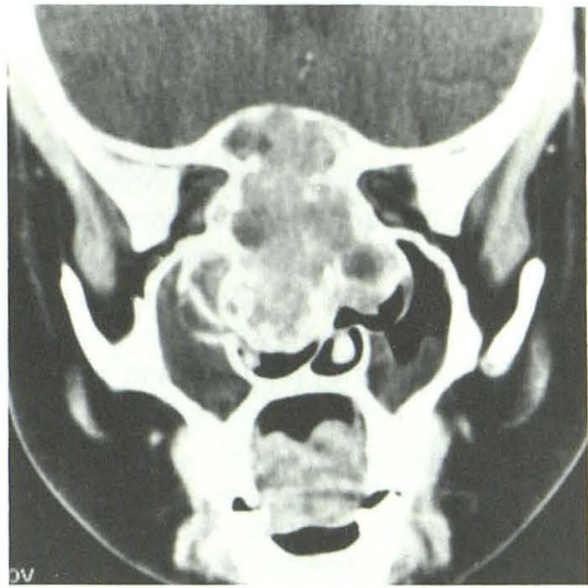

B

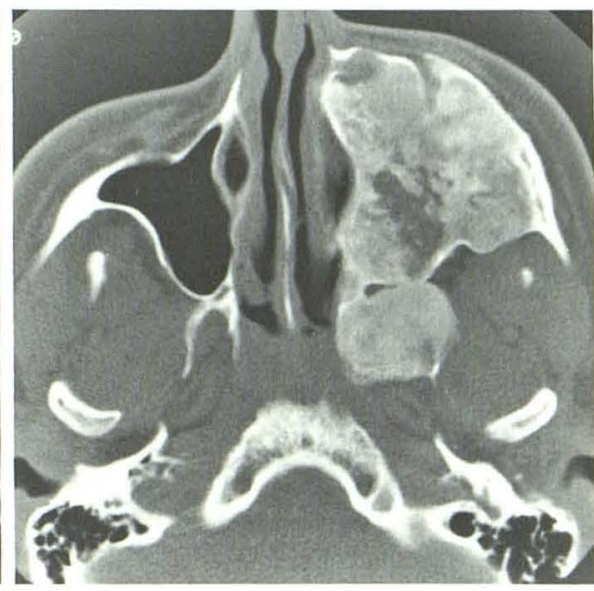

D

reported in other series [3-5, 11]. Toriumi et al. [9] recently reported a case of a large sphenoethmoid mucocele with hyperdensity on noncontrast $\mathrm{CT}$ and hypointensity on T1and T2-weighted MR images, similar to our four cases. At surgery, greenish, inspissated mucous was also found. These authors point out that the hypointense MR appearance can be a pitfall, in that the diseased sinus may be mistaken for an aerated sinus. This is not a problem with CT. A similar MR appearance of an expanded sinus with hypointense signal may also be seen in osteosarcoma, chondrosarcoma, and fibrous dysplasia of the facial bones due to weak signal from the matrix calcifications (Fig. 5).

Two of the four cases of mucoceles with signal void on MR also had pathologic diagnosis of allergic Aspergillus sinusitis. Patients with this disorder have a history of asthma, nasal polyps, chronic sinusitis, and sometimes mucocele formation [12]. The mucoid material from the sinuses characteristically contains eosinophils, Charcot-Leyden crystals, and fungal hyphae, indistinguishable from the bronchial mucous in allergic bronchopulmonary aspergillosis. The crystals may form from aggregation of granules from degenerated eosinophils [13]. Although the crystals could contribute to the signal dropout on MR, we think that the hypointensity is predomi-

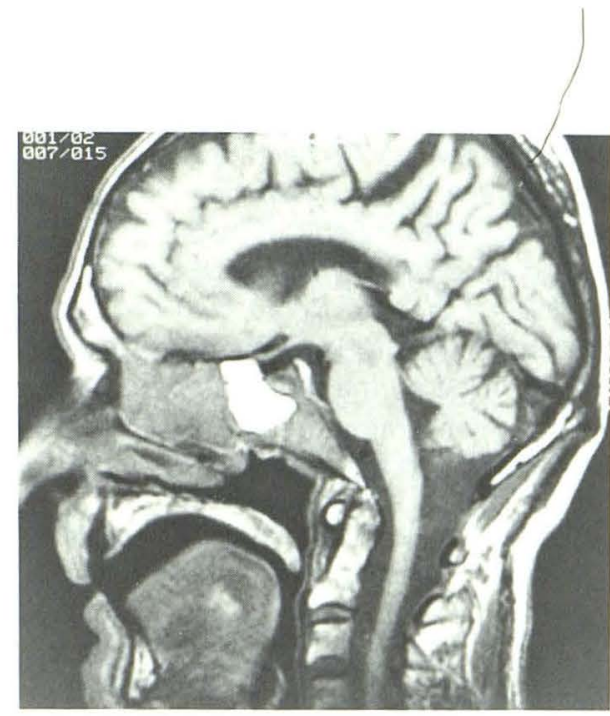

Fig. 6.-T1-weighted MR image $(600 / 20)$ shows small cell neuroendocrine carcinoma of ethmoid sinus invading the basisphenoid. Tumor displays isointense signal in ethmoids, nasal fossa, and within clivus, while obstructed secretions in sphenoid sinus are very hyperintense. 
nantly due to inspissated mucin. Variable signal intensity, including signal void, has been reported in aspergillus infection of the paranasal sinuses without mucocele formation $[7,14,15]$.

The uniformly bright signal intensity seen on T2-weighted images in the remaining two patients in this series correlates with an increased water content in these mucoceles. The obstructed sinuses in these cases also demonstrated bright signal intensity on T1-weighted scans, consistent with very proteinaceous sinus contents and more efficient $\mathrm{T} 1$ relaxation [16]. We have also seen several examples of tumors of the paranasal sinuses or nasal fossae obstructing a sinus ostium and causing retention of secretions prior to expansion of the sinus; these sinus contents exhibit the same bright signal on T1- and T2-weighted sequences (Fig. 6), easily demarcated from the isointense tumor. This pattern of T1 shortening and T2 lengthening can also be seen in subacute and chronic sinus hemorrhage $[17,18]$.

We have found that in most cases of paranasal sinus mucoceles, MR alone is sufficient for determining the extent of disease in preoperative imaging. However, as small areas of bone disruption will not be well seen on MR, at times preoperative CT may be very helpful for planning a transcranial or craniofacial surgical approach in cases with subtle involvement of the bone and dura of the anterior cranial fossa floor. Noncontrast CT also depicts with less confusion hyperdense, inspissated mucous. Owing to lack of signal on MR, this may be mistaken for an aerated sinus if gross expansion of the sinus is not also noted. On the other hand, MR can differentiate between sinus contents of low and high protein levels, which is not possible with CT. The very low or very high signal intensity MR patterns of mucoceles are easily distinguished from carcinomas of the paranasal sinuses, which are generally of isointense or intermediate signal on all MR imaging sequences [15 and Van Tassel, unpublished data]. The changes of acute and chronic sinusitis usually demonstrate isointense signal on T1-weighted scans and hyperintensity on T2-weighted images [7, 15].

In summary, the MR appearance of paranasal sinus mucoceles is quite variable, depending on the composition of the mucocele. Hypointense signal on T1-weighted images, becoming an area of signal void on T2-weighted images, is consistent with inspissated mucin. This appearance may also be influenced by the presence of Charcot-Leyden crystals in those patients with superimposed allergic Aspergillus sinusitis. The other appearance of mucoceles noted in this series consisted of hyperintense signal on both T1 and T2 type images, corresponding to more hydrated secretions, which are also high in protein content.

\section{REFERENCES}

1. Wigh R. Mucoceles of the fronto-ethmoidal sinuses. Radiology 1950; 54:579-590

2. Roberson GH, Patterson AK, El Deeb M, Maisel RH, Bone RC. Sphenoethmoidal mucocele: radiographic diagnosis. AJR 1976;127:595-599

3. Chui MC, Briant TDR, Gray T, Horsey WJ, Hudson AR, Tucker W. Computed tomography of sphenoid sinus mucocele. J Otolaryngol 1983;12(4):263-269

4. Hesselink JR, Weber AL, New PJ, Davis KR, Roberson GH, Taveras JM. Evaluation of mucoceles of the paranasal sinuses with computed tomography. Radiology 1979;133:397-400

5. Perugini S, Pasquini U, Menichelli F, et al. Mucoceles in the paranasal sinuses involving the orbit: CT signs in 43 cases. Neuroradiology 1982;23:133-139

6. Som PM, Shugar JMA. The CT classification of ethmoid mucoceles. $J$ Comput Assist Tomogr 1980;4(2):199-203

7. Lloyd GAS, Lund VJ, Phelps PD, Howard DJ. Magnetic resonance imaging in the evaluation of nose and paranasal sinus disease. $\mathrm{Br} J$ Radiol 1987;60:957-968

8. Lufkin RB, Stark DD, Hanafee WN. Neck, oropharynx, and nasopharynx. In: Stark DD, Bradley WG, eds. Magnetic resonance imaging. St. Louis: Mosby, 1988:735-791

9. Toriumi DM, Sykes JM, Russell EJ, Morganstein SA. Sphenoethmoid mucocele with intracranial extension: radiologic diagnosis. Otolaryngol Head Neck Surg 1988;98(3):254-257

10. Zizmore J, Noyek AM. Cysts, benign tumors, and malignant tumors of the paranasal sinuses. Otolaryngol Clin North Am 1973;6(2):487-508

11. Osborn AG, Johnson L, Roberts TS. Sphenoidal mucoceles with intracranial extension. J Comput Assist Tomogr 1979;3(3):335-338

12. Katzenstein AL, Sale SR, Greenberger PA. Allergic Aspergillus sinusitis: a newly recognized form of sinusitis. J Allergy Clin Immunol 1983;72:89-93

13. Katzenstein AL, Sale SR, Greenberger PA. Pathologic findings in allergic Aspergillus sinusitis: a newly recognized form of sinusitis. Am J Surg Pathol 1983;7:439-443

14. Zimmerman RA, Bilaniuk LT, Sze G. MRI of intracranial infection. In: Brandt-Zawadzki M, Norman D, eds. Magnetic resonance imaging of the central nervous system. New York: Raven, 1987:235-257

15. Som PM, Shapiro MD, Biller HF, Sasaki C, Lawson W. Sinonasal tumors and inflammatory tissues: differentiation with MR imaging. Radiology 1988;167:803-808

16. Bradley WG. Pathophysiologic correlates of signal alterations. In: BrandtZawadzki M, Norman D, eds. Magnetic resonance imaging of the central nervous system. New York: Raven, 1987:23-42

17. Som PM, Shugar JMA, Troy KM, Sacher M, Stollman AL. The use of magnetic resonance and computed tomography in the management of a patient with intra sinus hemorrhage. Arch Otolaryngol Head Neck Surg 1988; 114:200-202

18. Zimmerman RA, Bilaniuk LT, Hackney DB, Goldberg HI, Grossman RI. Paranasal sinus hemorrhage: evaluation with MR imaging. Radiology 1987;162:499-503 